\title{
GÊNEROS DO DISCURSO E ENSINO
}

\author{
Sheila Vieira de Camargo Grillo* \\ Ariadne Mattos Olímpio**
}

RESUMO: Descrição da presença da teoria do círculo de bakhtin nos pcns de língua portuguesa e investigação da forma/construção composicional dentro do projeto de uma metalingüística.

PALAVRAS-CHAVE: Ensino; Texto; Gêneros; Forma composicional.

INTRODUÇÃO

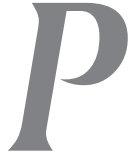

odemos constatar, em diversos momentos dos documentos oficiais para o ensino de língua portuguesa nos níveis fundamental e médio, que a abordagem do uso da língua deve considerar as esferas e os gêneros nos quais se realiza. Considerando que essas noções foram transpostas principalmente a partir da teoria do círculo de Bakhtin, ${ }^{1}$ cremos que uma breve exposição do seu sentido no conjunto da referida obra poderá contribuir para uma melhor compreensão do seu potencial de aplicação ao ensino. Antes disso, porém, faz-se necessá-

Professora da área de Filologia e Língua Portuguesa do Departamento de Letras Clássicas e Vernáculas da Faculdade de Filosofia, Letras e Ciências Humanas da Universidade de São Paulo (CNPq 401573/2004-4).

* Mestre em Filologia e Língua Portuguesa pelo Departamento de Letras Clássicas e Vernáculas da Universidade de São Paulo.

1 As divergências quanto à autoria nos levou, assim como a outros estudiosos, a optar pela designação "círculo de Bakhtin”, a fim de marcar a natureza coletiva da obra, evitando, desse modo, a atribuição da autoria exclusivamente a Mikhail Bakhtin. 
GRILLO, Sheila Vieira de C. e OLÍMPIO, Ariadne M. Gêneros do discurso e ensino.

rio nos perguntarmos sobre a pertinência dessa empreitada, em razão da existência do texto de Brait (2000) "PCNs, gêneros e ensino de língua” que já tocou nessa questão. O enfoque da autora recai sobre a distinção entre as noções de gênero discursivo e de tipologia textual, ${ }^{2}$ sobre a qual não nos deteremos, e sobre o papel dos falantes na modificação do gênero. Nossa proposta é, antes, investigar mais detidamente a natureza dialógica da categoria forma/construção composicional dos gêneros e a influência da esfera na sua organização.

\section{A NOÇÃO DE GÊNERO NOS PARÂMETROS CURRICULARES NACIONAIS $(P C N)$}

As propostas apresentadas nos Parâmetros Curriculares Nacionais (PCNs) de $3^{\circ}$ e $4^{\circ}$ Ciclos do Ensino Fundamental de Língua Portuguesa são embasadas na noção de gêneros do discurso desenvolvida pelo círculo de Bakhtin. Considera-se o texto a unidade de ensino da disciplina Língua Portuguesa, uma vez que é por meio dele, e não de frases ou orações, que utilizamos a linguagem. Dentre os objetivos dos PCNs está o de fazer os alunos usarem a linguagem nas diferentes esferas sociais, as quais, por sua vez, criam condições específicas para o uso da língua:

\footnotetext{
Interagir pela linguagem significa realizar uma atividade discursiva: dizer alguma coisa a alguém, de uma determinada forma, num determinado contexto histórico e em determinadas circunstâncias de interlocução. Isso significa que as escolhas feitas ao produzir um discurso não são aleatórias - ainda que possam ser inconscientes -, mas decorrentes das condições em que o discurso é realizado. (1998a, p. 20)
}

2 Na esteira de Rastier, entendemos os tipos de textos como classes que repousam sobre um único critério (por exemplo, a tipologia das sequiências textuais narrativa, descritiva, argumentativa, explicativa e dialogal de Jean-Michel Adam). $O$ tipo é atemporal e a proximidade ou a conformidade da ocorrência ao tipo é valorizada: trata-se da busca do melhor exemplo. 
Filol. lingüíst. port., n. 8, p. 379-390, 2006.

Cada esfera social cria seus tipos relativamente estáveis de enunciado os quais o círculo chama de gêneros do discurso. Os textos, produtos das atividades discursivas, se organizam dentro de determinados gêneros que são, de acordo com os PCNs, "determinados historicamente, constituindo formas relativamente estáveis de enunciados, disponíveis na cultura" (1998a, p. 21) e que são caracterizados por três elementos, intrinsecamente relacionados:

- conteúdo temático: o que é ou pode tornar-se dizível por meio do gênero;

- construção composicional: estrutura particular dos textos pertencentes ao gênero;

- estilo: configurações específicas das unidades de linguagem derivadas, sobretudo, da posição enunciativa do locutor; conjuntos particulares de sequiências que compõem o texto, etc. (1998a, p. 21).

Os diferentes gêneros, dessa forma, corresponderiam a uma família de textos que exibisse características semelhantes, ainda que heterogêneas, "como visão geral da ação à qual o texto se articula, tipo de suporte comunicativo, extensão, grau de literalidade, por exemplo, existindo em número quase ilimitado" (1998a, p. 22).

Uma outra semelhança com as noções do círculo, é a relevância do papel do outro no uso da linguagem, sendo a interlocução sua característica essencial: "Linguagem aqui se entende, no fundamental, como ação interindividual orientada por uma finalidade específica, um processo de interlocução que se realiza nas práticas sociais existentes nos diferentes grupos de uma sociedade, nos distintos momentos de sua história” (1998a, p. 20).

Assim, usamos a linguagem por meio de discursos moldados sob a forma de determinados gêneros cujos elementos - tema, construção composicional e estilo - levam em conta principalmente o interlocutor a quem o discurso está sendo endereçado. A passagem 
GRILLO, Sheila Vieira de C. e OLÍMPIO, Ariadne M. Gêneros do discurso e ensino.

a seguir reflete a relevância do outro no uso que fazemos da linguagem:

\begin{abstract}
(...) quando um sujeito interage verbalmente com outro, o discurso se organiza a partir das finalidades e intenções do locutor, dos conhecimentos que acredita que o interlocutor possua sobre o assunto, do que supõe serem suas opiniões e convicções, simpatias e antipatias, da relação de afinidade e do grau de familiaridade que têm, da posição hierárquica que ocupam. Isso tudo determina as escolhas do gênero no qual o discurso se realizará, dos procedimentos de estruturação e da seleção dos recursos linguísticos. É evidente que, num processo de interlocução, isso nem sempre ocorre de forma deliberada ou de maneira a antecipar-se à elocução. (1998a, p. 21)
\end{abstract}

Cabe à escola priorizar gêneros que caracterizem usos públicos da linguagem, como, por exemplo, dentre os escritos, a notícia, o editorial, o artigo de divulgação científica, o literário e, dentre os orais, o debate, a entrevista, o seminário. Simulando situações em que esses textos são realizados na esfera social, criam-se condições para que o aluno reflita criticamente, exercite formas de pensamento mais elaboradas e abstratas e, também, contemple a estética dos usos artísticos da linguagem. Pretende-se, desse modo, garantir participação plena numa sociedade letrada.

A noção bakhtiniana de diálogo está presente nessa condição primeira de uso da linguagem, isto é, deve-se sempre levar em conta o outro a quem um discurso é endereçado, mas também está presente no próprio texto, ou seja, há sempre marcas de outros textos que já foram produzidos: "Nesse sentido, os textos, como resultantes da atividade discursiva, estão em constante e contínua relação uns com os outros, ainda que, em sua linearidade, isso não se explicite. A esta relação entre o texto produzido e os outros textos é que se tem chamado intertextualidade" (1998a, p. 21).

A observação da intertextualidade é uma das sugestões para o ensino da língua identificadas nos Parâmetros Curriculares Nacionais para o Ensino Médio (PCNEM), que também conferem importância ao outro no estudo de um texto: 
Filol. lingüíst. port., n. 8, p. 379-390, 2006.

O texto verbal pode assumir diferentes feições, conforme a abordagem temática, a estrutura composicional, os traços estilísticos do autor - conjunto que constitui o conceito de gênero textual. A partir do pressuposto de que o texto pode ser uma unidade de ensino, sugere-se abordá-lo a partir de dois pontos de vista:

- Considerando os diversos aspectos implicados em sua estruturação, a partir das escolhas feitas pelo autor entre as possibilidades oferecidas pela língua;

- Na relação intertextual, levando em conta o diálogo com outros textos e a própria contextualização. (1998b, p. 60)

Logo após, os PCNEM afirmam que essas atividades podem partir não só do texto literário como também dos vários textos que circulam na esfera social. Como se vê, não se deve partir de um único gênero prototípico para o ensino da Língua Portuguesa, mas sim trabalhar com textos reais, presentes nas diferentes esferas da atividade humana.

\section{ORIGENS TEÓRICAS DA NOÇÃO DE GÊNERO NOS PCNS}

Os textos bakhtinianos das décadas de 1950, 1960 e 1970 esboçam o projeto de fundar um programa de pesquisa sobre os aspectos da linguagem não tratados pela linguiística saussureana de sua época. Esse projeto, que entendemos como uma síntese dos fenômenos desenvolvidos desde os anos 20 por ele e os outros membros do círculo, começa a se desenvolver de forma explícita a partir do texto "Os gêneros do discurso" (1953-1954), no qual Bakhtin estabelece a distinção entre a oração, enquanto unidade da língua, e o enunciado, que é uma unidade da interação ou da comunicação verbal. Bakhtin entende que a compreensão do enunciado auxiliará na compreensão da natureza das unidades da língua (palavras e orações). Esse programa de pesquisa, batizado como "translinguiística" 
GRILLO, Sheila Vieira de C. e OLÍMPIO, Ariadne M. Gêneros do discurso e ensino.

ou "metalinguiística", tem como objeto de estudo "as relações dialógicas (inclusive as relações dialógicas do falante com sua própria fala)". O dialogismo é a noção de base de todas as categorias de Bakhtin e de seu círculo desde os anos 20. Ele é a condição do sentido que se produz por meio da compreensão responsiva dos interlocutores, isto é, não há sentido fora da intersubjetividade e das relações dialógicas. As relações dialógicas, objeto da translinguiística, se manifestam entre os enunciados e no seu interior. Em resumo, todos os aspectos constitutivos do enunciado são de natureza dialógica.

O caráter dialógico do enunciado vai se manifestar também nos seus tipos relativamente estáveis ou gêneros do discurso. A noção de gênero ganha em visibilidade a partir do texto de Bakhtin dos anos 50, época na qual Bakhtin empreende, simultaneamente, o início de um esboço de programa de uma trans(meta)linguística, da qual o gênero seria parte constituinte, e as diferenças entre as unidades da língua e as unidades da interação verbal. Essa distinção permite ao autor decidir a questão dos gêneros do lado do enunciado e estabelecer seus aspectos constitutivos. Esses elementos são todos de natureza meta(ou trans)linguística: consequientemente, seu estudo ultrapassa a análise puramente linguiística e a abordagem do gênero deve considerar os aspectos dialógicos e extralinguiísticos da linguagem. Em seguida, a compreensão da categoria forma/construção composicional do gênero não se esgota no texto de Bakhtin dos anos 50, mas é preciso recuperá-la nos textos de Bakhtin, Medvedev e Volochinov dos anos 20 e 30.

\section{CONSTRUÇÃO/FORMA COMPOSICIONAL}

Entre os três aspectos do gênero em Bakhtin, a construção ou forma composicional é considerada seu elemento mais característico, tal como podemos notar pela expressão "acima de tudo" presente na definição de gênero do texto dos anos 50: "Esses enun- 
ciados refletem as condições específicas e as finalidades de cada referido campo não só por seu conteúdo (temático) e pelo estilo da linguagem, ou seja, pela seleção dos recursos lexicais, fraseológicos e gramaticais da língua mas, acima de tudo, por sua construção composicional." Esse aspecto é caracterizado como "tipo de estruturação e de acabamento do todo" e como "articulações composicionais". A compreensão desse aspecto passa, por um lado, pela discussão estabelecida nos anos 20 com a estética material e, por outro, pela inserção no projeto da trans(meta)linguiística.

No texto de 1924, "O problema do conteúdo, do material e da forma na obra literária” (Bakhtin, 1993), o autor critica a estética material e o método formal por tentar fundar uma ciência empírica positiva da obra de arte, apoiando-se sobre o princípio da primazia do material. Segundo Bakhtin, esse princípio pode produzir resultados fecundos sobre a técnica da obra de arte, mas ele é insuficiente para "explorar a obra global na sua singularidade e sua significação estética”. Entre os problemas da estética material, Bakhtin identifica a confusão entre as formas arquitetônicas e composicionais. A forma arquitetônica é entendida como "as formas de visão e acabamento artístico do mundo" (Bakhtin, 2003, p. 182) do objeto estético. É uma atividade artística que comporta os valores cognitivos e éticos e que dão sentido ao todo da obra literária. ${ }^{3}$ Esses valores se manifestam nas formas arquitetônicas literárias do lírico, trágico e cômico.

A forma composicional é a realização de uma forma arquitetônica por meio da organização de um material. Por exemplo, o trágico e o cômico se organizam na forma composicional do drama (diálogo, desmembramento em atos, etc.). Na obra literária, o material é a linguagem verbal. Essa organização se passa no nível da totalidade e da articulação das partes, dirigidas para uma finalidade. Em ter-

3 Para uma apresentação da noção de forma arquitetônica em Bakhtin, ver SOBRAL, A. Ético e estético. In: BRAIT, Beth (Org.) (2005) Bakhtin: conceitos-chave. São Paulo, Contexto, p. 103-22. 
GRILLO, Sheila Vieira de C. e OLÍMPIO, Ariadne M. Gêneros do discurso e ensino.

mos da totalidade, Bakhtin cita como exemplos de formas composicionais os gêneros romance, drama, poema, notícia: "Deve-se ter em vista que cada forma arquitetônica é realizada por meio de métodos composicionais definidos; por outro lado, às formas composicionais mais importantes, às de gênero por exemplo, correspondem, no objeto realizado, formas arquitetônicas essenciais" (Bakhtin, 1993, p. 24). É preciso observar que, nesse texto, o gênero equivale à forma composicional. Em termos de articulação das partes, são mencionados o capítulo, a estrofe, o verso, o parágrafo, as linhas, as palavras. Em síntese, a forma composicional encontra-se no nível da organização textual. Essa noção será retomada, articulada à teoria do enunciado, no texto dos anos 50 .

Em termos epistemológicos, a construção/forma composicional revela a natureza "meta(trans)linguiística" do gênero. Em primeiro lugar, seu volume extremamente variado ultrapassa a proposição ou a oração, enquanto unidade da língua, e coloca problemas metodológicos para a linguiística: "Uma das causas do desconhecimento linguiístico das formas de enunciado é a extrema heterogeneidade destas no tocante à construção composicional e particularmente à sua dimensão (a extensão do discurso) - da réplica monovocal ao grande romance" (Bakhtin, 1952-1953, p. 286). Esse tipo de crítica está também presente na obra Marxismo e filosofia da linguagem, o que reforça nossa visão da coerência do projeto do círculo. Apesar de a forma composicional pertencer ao enunciado, ela não pode ser apreendida pelos métodos da linguiística da oração. Em seguida, a inserção da construção/forma composicional no projeto da meta(trans)linguiística é ainda mais claro, quando se percebe que as relações dialógicas entre os parceiros do enunciado estão na base de sua estruturação. A esse propósito, encontramos, uma vez mais, uma harmonia entre o texto de Bakhtin dos anos 50 e o texto disputado dos anos 20, Marxismo e filosofia da linguagem:

Ao falar, sempre levo em conta o fundo aperceptível da percepção do meu discurso pelo destinatário: até que ponto ele está a par da situação, dispõe de conhecimentos especiais de um dado campo cultural da comunicação; 
Filol. lingüíst. port., n. 8, p. 379-390, 2006.

\begin{abstract}
levo em conta as suas concepções e conviç̧ões, os seus preconceitos (do meu ponto de vista), as suas simpatias e antipatias - tudo isso irá determinar a ativa compreensão responsiva do meu enunciado por ele. Essa consideração irá determinar também a escolha do gênero do enunciado e a escolha dos procedimentos composicionais e, por último, dos meios linguiísticos, isto é, o estilo do enunciado. (Bakhtin, 1952-1953/2003, p. 302) Na base da divisão do discurso em partes, denominadas parágrafos na sua forma escrita, encontra-se o ajustamento às reações previstas do ouvinte ou do leitor. Quanto mais fraco o ajustamento ao ouvinte e a consideração das suas reações, menos organizado, no que diz respeito aos parágrafos, será o discurso. (Bakhtin/Nolochinov, 1929/1992, p. 141)
\end{abstract}

O modo de organização do todo e de divisão de suas partes são subordinados, conforme explicitado nesses fragmentos, pelos conhecimentos e reações presumidos do ouvinte/leitor previsto. Percebemos aqui tanto os reflexos das distinções saídas da crítica ao método formal, com a diferenciação entre forma arquitetônica e composicional, quanto a influência do projeto da meta(trans)linguiística de estudar as relações dialógicas, expressas em todos os aspectos do enunciado e de seus gêneros, aí compreendida a construção/ forma composicional.

A fim de observar a pertinência do projeto do círculo para a análise de gêneros do discurso, selecionamos uma reportagem de divulgação científica do jornal paulista $O$ Estado de S. Paulo.

CIÊNCIA

Células do ouvido podem se regenerar

Capacidade permitiria a reversão de algumas formas de surdez

Lívia Deodato

As células sensoriais do ouvido interno de mamíferos podem ter a capacidade de se regenerar. A conclusão é de um estudo publicado na semana passada pela revista britânica Nature.

Essa capacidade permitiria a reversão de alguns tipos de surdez, como as adquiridas por barulhos estridentes ou pelo uso de certas drogas. "Na pesquisa que realizamos não observamos a regeneração nos próprios animais, apenas em culturas de laboratório", explica ao Estado Andrew Groves, do Instituto House Ear de Los Angeles, EUA, um dos responsáveis pela pesquisa. 
GRILLO, Sheila Vieira de C. e OLÍMPIO, Ariadne M. Gêneros do discurso e ensino.

\begin{abstract}
A pesquisa sobre regeneração de células do cóclea, área responsável pela audição anterior ao labirinto (ou ouvido interno), começou em 2000. Outras equipes, porém, se debruçam sobre o tema há mais de 20 anos. "Já foi comprovado por outros cientistas que os pássaros podem regenerar suas células do ouvido interno após ficarem surdos", diz Groves.

Isso ocorre porque as células chamadas de apoio se dividem e se transformam em novas células sensoriais após o dano. "Assim, um pássaro que antes era surdo poderá ouvir normalmente após três ou quatro semanas." Os estudos com ratos recém-nascidos ajudaram a entender o procedimento de regeneração de células sensoriais.

"Quando agrupamos células purificadas e deixamos elas crescerem em uma cultura, descobrimos que $50 \%$ conseguiam se dividir e, algumas delas, se transformar em células sensoriais", conta Groves.

No entanto, quando repetiram o experimento com ratos mais velhos, descobriram que as células de apoio não mais conseguiam se dividir. "As células de ratos mais velhos não se dividem porque não têm a capacidade de desativar um gene chamado p27, que têm como função não deixar que as células se dividam", explica. "Já as células mais jovens conseguem desativar o p27 e se dividir, uma vez colocadas em cultura." Os pesquisadores ainda não descobriram quais são os motivos responsáveis pela incapacidade de células mais velhas de desativar o gene.

O objetivo da pesquisa é encontrar maneiras de superar esses percalços, entre eles, o de fazer com que células envelhecidas consigam se regenerar, para assim poder ajudar humanos a recuperar a audição sem uso de aparelho.

(O Estado de S. Paulo, 27/06/2006, p. A13, VIDA\&)
\end{abstract}

A compreensão da forma composicional dessa reportagem passa pela consideração do seu diálogo com o leitor presumido e com os enunciados anteriores, o qual se materializa na relação entre o peritexto e a ordenação dos parágrafos com o seu conteúdo temático. Nessa reportagem, a forma composicional inscreve-se no que os jornalistas chamam de "pirâmide invertida", pois os parágrafos ordenam-se em função do grau de importância do tema, de modo que os primeiros parágrafos concentram as informações consideradas mais relevantes e atraentes ao leitor. Em consequiência, a estrutura dessa reportagem de divulgação científica organiza-se da seguinte forma:

Peritexto: esfera, conclusão e possibilidade de aplicação terapêutica da pesquisa 
Filol. lingüíst. port., n. 8, p. 379-390, 2006.

$1^{\circ}$ par. Conclusão da pesquisa

$2^{\circ}$ par. Possibilidade de aplicação terapêutica da pesquisa

$3^{\circ}$ par. Breve histórico da área de pesquisa

$4^{\circ}$ par. Explicação de resultados de outras pesquisas

$5^{\circ}$ par. Procedimentos experimentais

$6^{\circ}$ par. Limites dos conhecimentos atuais

$7^{\circ}$ par. Objetivos da pesquisa

Essa organização evidencia que o texto de divulgação científica na esfera jornalística segue uma ordenação inversa ao texto científico (objetivos, procedimentos, conclusões, aplicações) e que a captação do leitor se dá sob a presunção do seu interesse pelos resultados e aplicações das pesquisas mais do que pelo próprio saber científico construído. O parágrafo se constitui na principal articulação composicional da reportagem, cada um podendo sintetizar o que corresponderia a uma seção inteira de um artigo científico.

A ordenação dos parágrafos se alia a procedimentos de incorporação e de transmissão de enunciados alheios. Dois gêneros estão intercalados nessa reportagem: a menção, no primeiro parágrafo, a um "estudo" da revista britânica Nature, e a transcrição de fragmentos de uma entrevista com um pesquisador. O "estudo" é provavelmente um artigo científico e não sabemos, em que medida, ele serviu de fonte primária ao jornalista. A entrevista, por outro lado, não é mencionada enquanto gênero, mas pode ser depreendida pela utilização dos verbos de elocução "explica", "diz", "conta" e "explica", que marcam, ao mesmo tempo, a transmissão objetiva e o papel explicador do cientista. A inserção desses gêneros ocorre de forma a legitimar a mediação da reportagem jornalística e a inserir a ciência na esfera jornalística. Por fim, os parágrafos apresentam uma grande variedade composicional (explicação, breve narrativa do percurso da pesquisa, descrição de objetivos), adequada ao necessário diálogo que o gênero reportagem de divulgação científica deve realizar com enunciados da esfera científica. 
GRILLO, Sheila Vieira de C. e OLÍMPIO, Ariadne M. Gêneros do discurso e ensino.

\section{CONSIDERAÇÕES FINAIS}

A noção de gênero do discurso se insere no projeto do círculo de Bakhtin de fundar uma meta/translinguiística, que se ocuparia das relações dialógicas do enunciado. Nesse sentido, procuramos evidenciar que a forma composicional organiza-se de modo dialógico e incorpora os condicionamentos das esferas nas quais circulam os gêneros. Com isso, esperamos contribuir para a compreensão da teoria do círculo presente nos PCNs de língua portuguesa.

\section{BIBLIOGRAFIA}

BAKHTIN, Mikhail. (1997). Problemas da poética de Dostoievski. Trad. Paulo Bezerra. 2. ed. Rio de Janeiro: Forense Universitária. (Original russo: 1963.)

. Estética da criação verbal. (2003). Trad. Paulo Bezerra. São Paulo: Martins Fontes. (Original russo: 1952-1953)

. Questões de literatura e estética: a teoria do romance. (1993) Trad. A. F. Bernadini et al. 3. ed. São Paulo: Ed. Unesp. (Originais russos: 1924-1970)

BAKHTIN, M. M.; MEDVEDEV, P. N. (1991). The formal method in literary scholarship: a critical introduction to sociological poetics. Trad. A. J. Wehrle. Baltimore/London: Johns Hopkins Press. (Original russo: 1928)

BAKHTIN, M. M.NOLOCHINOV, V. N. (1992). Marxismo e filosofia da linguagem. Trad. Michel Lahud e Yara Frateschi Vieira. 6. ed. São Paulo: Hucitec. (Original russo, 1929)

BRAIT, B. (2000). PCNs, gêneros e ensino de língua: faces discursivas da textualidade. In: ROJO, R. (Org.). A prática de linguagem em sala de aula. São Paulo: Mercado de Letras.

SEB (1998a). Parâmetros Curriculares Nacionais: terceiro e quarto ciclos do ensino fundamental: Língua Portuguesa. Brasília: MEC/SEB.

SEB (1998b). Parâmetros Curriculares Nacionais para o Ensino Médio: Língua Portuguesa. Brasília: MEC/SEB.

ABSTRACT: Description of the bakhtin's circle theory in the pcns of portuguese language and the investigation of the compositional structure in the metalinguiistics project.

KEYWORDS: Education; Text; Genres; Compositional structure. 